\title{
Agricultural Statistics for Developing Countries: Where Do We Stand?
}

\author{
Alessandra Pelloni ${ }^{1 *}$ and IlariaTedesco ${ }^{2}$ \\ ${ }^{1}$ Department of Economics and Finance, University of Rome Tor Vergata, Italy \\ ${ }^{2}$ Platform for Agricultural Risk Management, International Fund for Agricultural Development, Italy
}

*Corresponding author: Alessandra Pelloni, Department of Economics and Finance, University of Rome Tor Vergata, Italy.

Received Date: March 11, 2020

Published Date: May 11, 2020

\begin{abstract}
Agriculture is recognised as an essential engine for inclusive growth and poverty reduction in developing countries. However, the quantity and quality of available data and indicators in these countries is still insufficient to properly inform policy, due to decades of under-investment in data collection. The much-needed renewal process will require a protracted effort by both individual countries and multilateral agencies.
\end{abstract}

Keywords: Agriculture; Developing countries; Data; Productivity

\section{Introduction}

The attention to progress in agriculture by international organizations, donors as well as national policy makers is increasing. The Sustainable Development Goal 2, "End hunger, achieve food security and improved nutrition and promote sustainable agriculture", features prominently among the United Nations new 17 Sustainable Development Goals (UN General Assembly) [1].

More specifically the aim is to: "By 2030, double the agricultural productivity and incomes of small-scale food producers, in particular women, indigenous peoples, family farmers, pastoralists and fishers, including through secure and equal access to land, other productive resources and inputs, knowledge, financial services, markets and opportunities for value addition and nonfarm employment" (Target 2.3).

In fact, more than 60 percent of workers in poorer countries are employed in agriculture, whose low productivity is a major cause of poverty. Indeed, growth in the sector has been estimated to be two to four times more effective in raising incomes among the poorest compared to other sectors [2].
The state of agriculture in Africa is particularly dire. Many of the programs in support of agriculture were dismantled in the 1970s by the World Bank, from subsidies for fertilizers and seeds to guaranteed prices for crops and funds for agricultural R\&D. These policies supported Asia so called Green Revolution in the 60s, which by-passed Africa. However, in the new millennium an important change in attitudes towards African agriculture has occurred. In Maputo, in 2003, the African Union (AU) Summit made the first declaration on CAADP (Comprehensive Africa Agriculture Development Programme) as an integral part of the New Partnership for Africa's Development : "Agriculture is everyone's business: national independence depends on its development because it enables us to escape the scourge of food insecurity that undermines our sovereignty and fosters sedition; it is a driver of growth whose leverage is now acknowledged by economists and politicians; it is the sector offering the greatest potential for poverty and inequality reduction, as it provides sources of productivity from which the most disadvantaged people working in the sector should benefit." In 2016, with the Malabo declaration on Accelerated 
Agricultural Growth and Transformation for Shared Prosperity and Improved Livelihoods, the Heads of State and Governments of the African Union committed to ending hunger in Africa by resolving to "accelerate agricultural growth by at least doubling current agricultural productivity levels, by the year 2025" (AU) $[3,4]$.

In view of these ambitious policy aims, understanding the mechanisms and driving factors behind agricultural productivity growth is of tantamount importance A preliminary question, however, arises: are the available data good enough to formulate evidence-based policy? Following decades of neglect, the answer is no, in spite of recent efforts such as the Global Strategy to Improve Agricultural and Rural Statistics whose focus is to develop new protocols and to promote best practices for the estimation of agricultural indicators (World Bank, United Nations and FAO) [5] or the Living Standards Measurement Study - Integrated Surveys on Agriculture (LSMS-ISA), an important household survey project established with a grant from the Bill and Melinda Gates Foundation.

As of yet, the quality of data for agriculture is generally poor, and in fact the poorest countries-for which agriculture is by far the main economic activity-often have the worst data.

\section{Discussion}

Carletto et al. [6] analyses the problem in detail. At the national level, data may come from different and uncoordinated institutions (e.g. the Ministry of Agriculture and the National Statistical Office). Donors can help in providing the financial and human resources to collect more data, but their support is often variable through time resulting in sparse data.

The three major sources of data are: 1) Routine data systems maintained by the Ministry of Agriculture, which exist in basically all countries but are characterized by a high degree of arbitrariness in collection protocols; 2) Agricultural census data, which FAO recommends countries to collect every ten years. However, because of their high costs agricultural censuses are becoming less frequent; 3) Sample surveys data. Farm surveys are the most important agricultural statistics in Africa, even if their exclusive focus on the measurement of agriculture does not take into account the diversification of income sources even at the individual level that prevails in rural areas. In many countries, there are other types of household surveys, conducted by national statistics offices or private organizations that provide some information on agriculture.

The integration of different data sources is one of main objectives of the Global Strategy. The most effective way for the integration of different data files would be to have standard identifiers in each file allowing data from different agencies and institutions to be merged. In fact, in many countries the data collected by the Ministries of Agriculture are not linked with data coming from other sources such as the National Statistical Offices or Ministries of Labour, Education and Health. Two further causes of poor agricultural data are on the hand the lack of rigorous research, which depresses demand for high-quality data and on the other hand, the fact that data may be of interest for various political and institutional players (national governments, donors and collecting agencies) and may therefore be the result, to some extent, of political negotiations $[7,8]$.

We now come to the problems specifically raised by the measurement of agriculture productivity. FAO [9] like Carletto et al. [6] laments the qualitative and quantitative limitations of available agricultural productivity measures due to insufficient statistical infrastructure and lack of appropriate data collection protocols.

Productivity is generally defined as a ratio of a measure of outputs to a measure of inputs and can therefore be calculated in many ways, considering a single factor of production or multiple ones. Measuring agricultural outputs with precision is itself very problematic in less advanced countries. In fact, many farmers consume the largest share of their production, which is therefore not priced. Valuation is generally based on market prices, which however vary frequently throughout the year. The common practice of growing several crops on the same parcel of land adds complexity to the measurement. Indeed, the accuracy in production estimates varies widely across crops, being much higher for marketed crops like grains, and much lower for extended-harvest crops like cassava or bananas. Kelly et al. [10] found that the underestimation of output from secondary crops and by-products is particularly severe. Hopkins and Berry [11] estimated that in Niger, labour productivity was 20 per cent lower when only the principal crop was accounted for.

Another problem is the use of non-standard units (e.g. bunches not kilograms of bananas). Coming to collection methods, [12] shows that harvest diaries are more reliable than recall methods but less commonly used because more time-consuming for respondents. The measurement of inputs is likewise complicated. The inputs mainly considered are labour and land.

Labour productivity is calculated as a ratio of number of units of output(s) produced per unit of labour. Units of labour can be the number of active workers in the sector or the number of time units (such as hours, days and months) worked in full-time equivalent units (FAO) [9]. A big obstacle to the calculation of units of labour is that agriculture in poor countries falls largely into the informal sector, so that most workers in the sector are unpaid family members and own-account workers, rather than employees. This may lead to over- counting the number of workers because some people might be mistakenly counted as active in agriculture simply because they live in rural areas. Over-counting the labour input might also occur if hours worked are systematically lower in agriculture.

Data on active workers in the agricultural sector are availablealthough scattered - for different countries and years but the use of the number of hours effectively worked is recommended by OECD [13] to correct for biases such as seasonality, variability in working time and unpaid owner and family-supplied labour arising when the number of workers is used as indicator. 
Data on number of hours effectively worked in agriculture are very limited. ILOSTAT provides several indicators on labour, including hours of work and labour productivity but they are not disaggregated by sector and are only available for few years. ILOSTAT also warns that "Imputed observations are not based on national data, are subject to high uncertainty and should not be used for country comparisons or rankings" (ILOSTAT website, 2018).

Another reason why the number of workers may not be an accurate measure of the labour input effectively used in the agricultural sector is the different quality of workers. In fact, workers with different skills and abilities, due to age, health or education have different levels of productivity. Ignoring the differences between workers with different levels of human capital, will lead to biased estimates of labour productivity.

Gollin et al. [14] looking at national accounts data from 151 countries find that value added per worker is roughly three times higher on average in non-agricultural sectors than in agriculture. The productivity gaps are unsurprisingly larger for poorer countries: for economies at the 90th percentile of the distribution of income, the gap is 6.8. They then compute "adjusted" agricultural productivity gaps, taking into consideration the sector differences in hours worked and human capital from micro data and find that with these adjustments the median and mean gap decreased by nearly 50 percent in the least developed countries. McCollough [15] using LSMS-ISA data for four African countries (Ethiopia, Malawi, Tanzania and Uganda), finds that the average agricultural worker spends only 700 hours yearly on the job while the non-agricultural worker works for 1850 hours on average, so that, on a per-hour basis, labour in non-agricultural sectors is only 1.4 times more productive than in agriculture.

Another key indicator for agricultural productivity is land productivity. If accurately measured, this indicator helps determine incentives for land use change, returns to landowners, and consumer food prices [16]. Land productivity is calculated either as the value of all agriculture products (crops and livestock) over the total land used (planted or harvested) or as the ratio between crop production and the planted land.

Among the different land size, FAOSTAT expresses its crop yield statistics in terms of production quantity over area harvested while FAO [9] warns that the use of harvested area instead of planted area can lead to an overestimation of yields as the quantity expressed reflects only the output of most productive segments of the land. In many cases land size variables are self-reported measurements from household surveys which tend to show an upward bias when compared with GPS- measurements [17].

Finally, it must be stressed that measures of land and labour productivity cannot be used interchangeably: an increase in land productivity may be due to more intensive farming i.e. correspond to an increase in labour, whose productivity may be declining. For instance, Pelloni et al. [18] show that foreign aid given to agriculture for productive purposes tend to have a stronger effect on land productivity than on labour productivity.

\section{Conclusion}

To sum up, serious weaknesses persist in the measurement of agricultural outcomes in less developed countries, especially as regards smallholder agriculture. To end on a higher note, new technologies can greatly assist in overcoming these weaknesses, just think of satellite imagery or computer assisted personal interviewing not to mention cell phones, which are proving essential in providing information to isolated rural communities. The decreasing costs of GPS units make the collection of georeferenced information now possible on a large scale. Linking data from farm and household surveys with information from remote sensing could allow a much deeper and wider understanding of agricultural issue Since 2015, Big Data investors have been investing hundreds of millions of USD into agricultural start-ups to transform agriculture [19]. Collecting, processing and analyzing large volume of structured and unstructured data with new digital tools could in principle enormously enrich our knowledge of the agricultural sector in developing countries.

However the structural criticalities of the statistical systems in poorer counties, from the lack of coordination in data collection to the lack of analytical capacity in examining the data have to be properly addressed for the digitalization of agriculture now underway to become a key tool in the formulation of effective policies.

\section{Acknowledgement}

None.

\section{Conflict of Interest}

No conflict of interest.

\section{References}

1. (2015) UN General Assembly Transforming our world: the 2030 Agenda for Sustainable Development.

2. Townsend R (2015) Ending poverty and hunger by 2030: an agenda for the global food system (English). World Bank Group: Washington, USA, pp: 29.

3. (2004) African Development Bank the Marrakech Action Plan for Statistics: Better Data for Better Results: An Action Plan for Improving Development Statistics. 2nd International Roundtable on Managing for Development Results. Marrakech, Morocco, Africa.

4. (2014) African Union (AU) Malabo Declaration on accelerated agricultural growth and transformation for shared prosperity and improved livelihoods. Malabo, Guinea Bissau: African Union, Africa.

5. (2010) World Bank, FAO, and United Nations Global strategy to improve agricultural and rural statistics. World Bank Group: Washington, USA, pp: 39.

6. Carletto C, Jolliffe D, Banerjee R (2015) From tragedy to renaissance: improving agricultural data for better policies. J Dev Stud 51(2): 133148. 
7. Jerven M (2013) The political economy of agricultural statistics and input subsidies: Evidence from India, Nigeria and Malawi. Journal of Agrarian Change.

8. Sandefur J, Glassman A L (2014) The political economy of bad data: Evidence from African survey \& administrative statistics. SSRN Electronic Journal 51(2).

9. (2017) Food and Agriculture Organization of the United Nations (FAO) Productivity and efficiency measurement in agriculture, literature review and gaps analysis. Global Strategy to Improve Agricultural and Rural Statistics. Technical Report Series GO-19-2017. FAO: Rome, Italy.

10. Kelly V A, Hopkins J, Reardon T, Crawford EW (1996) Improving the measurement and analysis of African agricultural productivity promoting complementarities between micro and macro data. Technical Paper No. 27 Office of Sustainable Development, Bureau for Africa, USAID publication, Washington, USA.

11. Hopkins J, Berry P (1994) Determinants of land and labor productivity in crop production in Niger. Report to the United States Agency for International Development/Niger. International Food Policy Research Institute: Washington, USA.

12. Deininger K, Carletto C, Savastano S, Muwonge J (2012) Can diaries help in improving agricultural production statistics? Evidence from Uganda. Journal of Development Economics, 98(1): 42-50.
13. (2001) Organization for Economic Cooperation and Development Measuring productivity. OECD manual: Measurement of aggregate and industry-level productivity growth. OECD: Paris, France.

14. Gollin D, Lagakos D, Waugh M E (2014) The agricultural productivity gap. Quart J Econ 129(2): 939-993.

15. McCullough EB (2017) Labor Productivity and Employment Gaps in SubSaharan Africa. Food Policy 67: pp. 133-152.

16. Wiebe K D (2003) Linking quality, agricultural productivity, and food security. Agricultural Economic Report 823. U.S. Department of Agriculture, Pp: 60.

17. Carletto C, Savastano S, Zezza A (2013) Fact or artifact: The impact of measurement errors on the farm size-productivity relationship. Journal of Development Economics 103: 254-261.

18. Pelloni A, Stengos D, Tedesco I (2019) Aid to agriculture, trade and structural change. Metroeconomica, pp: 1-24.

19. Trendov NM, Varas S, Zeng M (2019) Digital technologies in agriculture and rural areas-Status report. FAO: Rome, Italy. 